\title{
Shunt active filter using fuzzy logic based on three-level (NPC) inverter to compensate current harmonics
}

\author{
Loutfi Benyettou*, Mustapha Tebbakh \\ Laboratory of Electrical Engineering, University of M'sila, Algeria
}

Corresponding Author Email: benyettou.loutfi_lge@yahoo.fr

https://doi.org/10.18280/ama_b.610404

Received: 19 July 2018

Accepted: 5 November 2018

\author{
Keywords: \\ Three-level (NPC), Shunt active power \\ filter, harmonic distortion (THD),
}

hysteresis, fuzzy logic controller

\begin{abstract}
In this paper, a three-level (NPC) shunt active power filter based on fuzzy logic controller is modeled, simulated, and tested. The fundament of Instantaneous Reactive Power Algorithm is used for extracting compensated reference harmonic current. A fuzzy logic controlled shunt Active Power Filter Using Hysteresis Band Current is applied to regulate the DC capacitor voltage of shunt Active Power Filter in order to improve the active filter dynamic, to ensure sinusoidal source currents and to produce a high power quality. The main goal of the proposed active filtering system is to maintain the THD well within IEEE on harmonics levels. Simulation results through MATLAB/Simulink are presented and interpreted. It is demonstrated that the fuzzy logic controller improves the performance of the active power filter.
\end{abstract}

\section{INTRODUCTION}

The power pollution drawn from nonlinear loads such as switching mode power supplies, commercial lighting, ovens, and adjustable speed drives results in the degradation of power quality in the distribution system. The non-sinusoidal balanced or unbalanced currents generate harmonics, reactive power, and excessive neutral current. Conventionally, passive filters have been used to eliminate current harmonics and increase the power factor. However, the use of passive filter has many disadvantages. Recently, active power filters [1] have been widely studied for the compensation of harmonic and reactive currents in power systems. Shunt active power filters are operated as an ideal current source which can provide a dynamic and adjustable solution for eliminating the harmonic currents and compensating the reactive power by injection of compensation currents [2]. The most powerful converter used has been the two-level voltage source inverter [3]. However, due to power handling capabilities of power semiconductors, these inverters are limited for low power applications. Threelevel inverters have been successfully employed in medium and high power applications in the past years [4-5]. The advantages of these inverters are lower voltage harmonics on the A.C. side, smaller filter size, lower switching losses, lower electromagnetic interference, lower voltage stress of power semiconductors and lower acoustic noise. These advantages can reduce the construction cost of active filter in the medium and high voltage applications. The controller is the core of the active power filter operation and has been the subject of numerous researches in recent years. The conventional control scheme to generate pulses based on hysteresis controller presents several drawbacks. To improve the shunt APF performance the tendency in power electronics applications is to use intelligent control techniques. This paper presents two control schemes for three-level (NPC) shunt active filter based on hysteresis and fuzzy logic controllers. The models and numerical simulation for transient and steady-state conditions are developed and performed using Matlab/Simulink program.

\section{DESCRIPTION OF THE APF TOPOLOGY}

Fig. 1 presents a classical three-level shunt active power filter system. It is composed of a grid (esi for $i=\{1,2,3\}$ ), a non-linear load, a voltage source converter. The load is a three phase diode rectifier feeding a series $(\mathrm{R}, \mathrm{L})$ load. The grid is supposed to be balanced with equal series resistance Rcc and inductance Lcc for each phase. The static converter is a voltage source inverter with equal series inductance $\mathrm{Lf}$ for each phase [6-7].

The output currents of the shunt active filter are controlled by Hysteresis controllers and fuzzy logic controller to provide reactive power and harmonic currents generated by the nonlinear load to ensure filtering. Several faulty cases can occur: power switch or power switch driver can be faulty. In each case, it results in the following models:

A switch is closed instead of being normally open.

It results in a short-circuit of the DC voltage source, increasing is 123 current. To isolate the faulty switch as fast as possible, one can use fuses.

A switch is open instead of being normally closed. It results in an open phase. The filter may continue injecting currents to the power supply. These currents don't cause any prompt risk because they are at the same range level as the case of no-fault condition. However, the filter in this case is polluting more the power supply instead of elimination of harmonic currents of non-linear load. This case is considered in this paper. 


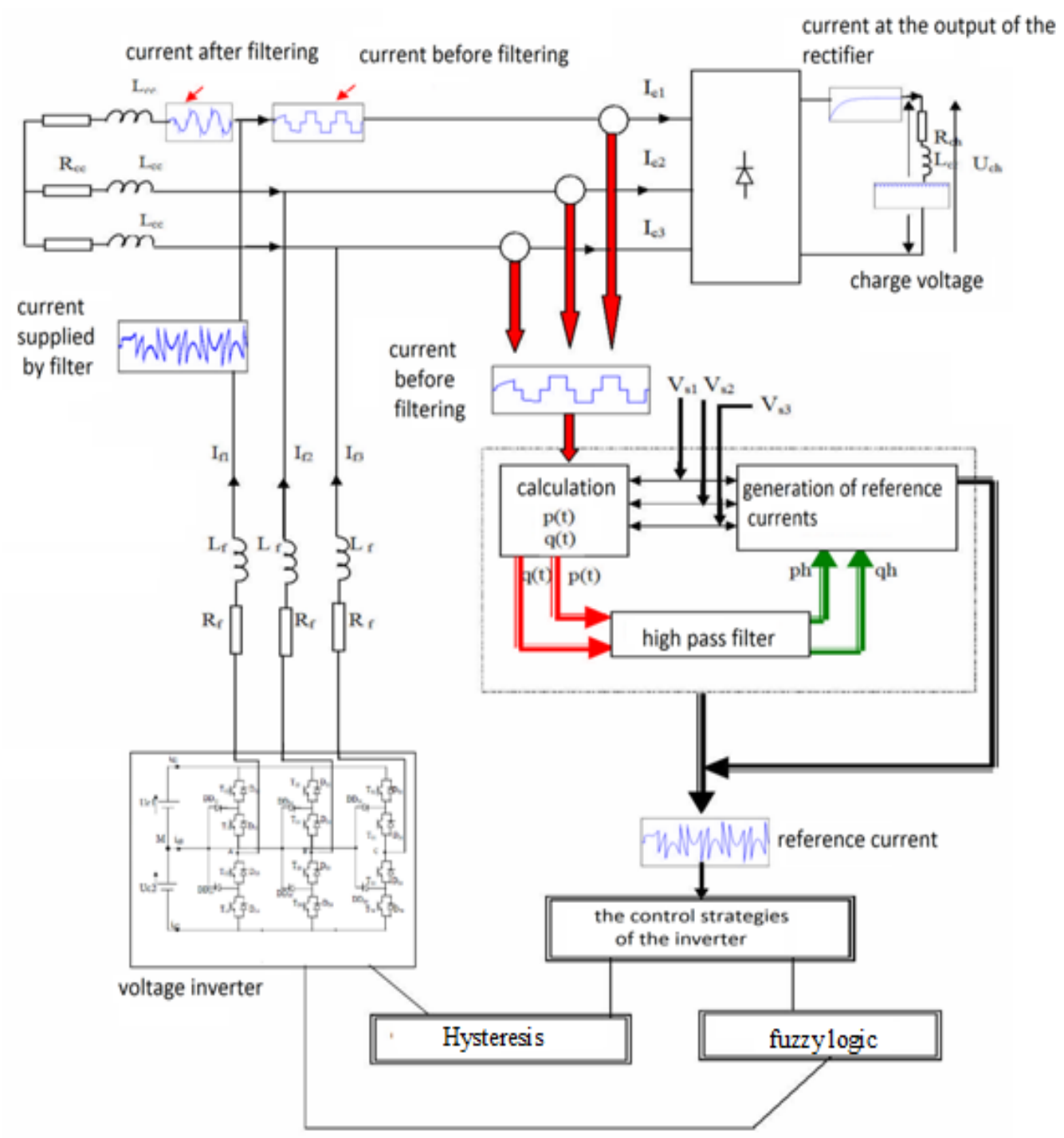

Figure 1. Active power filter operation

\subsection{Three-level voltage inverter}

Fig.2, describes the structure of three-level voltage inverter. The diodes are used to make the connection with the point of reference $\mathrm{O}$ to obtain Midpoint voltages. In order to produce a voltage of $\mathrm{N}$-Levels, $\mathrm{N}-1$ capacities are required. The voltage across each condenser is equal to $\mathrm{E} /(\mathrm{N}-1), \mathrm{E}$ is the total voltage of the DC source. Each couple of switches (S1, S3) form a cell of commutation, the two switches are ordered in a complementary way [8].

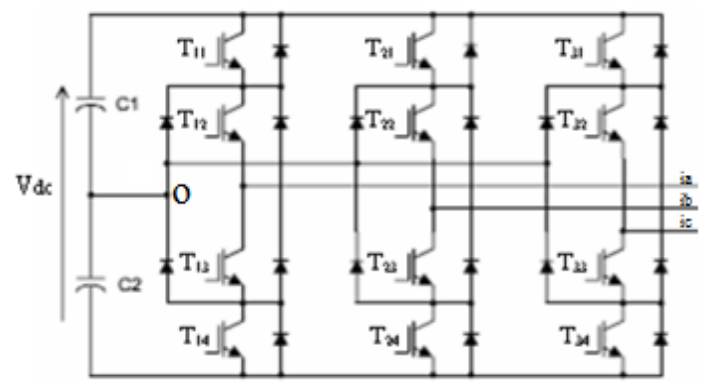

Figure 2. Structure of three-level voltage inverter

The inverter provides three voltage levels according to (1) $v_{i o}=K_{i} \cdot E / 2$

where

Vio: is the phase-to-middle fictive point voltage

$K i$ : is the switching state variable $(K i=1,0,-1)$

$E$ : is the DC source voltage

$i$ : is the phase index $(i=a, b, c)$. The three-level voltages are shown in Table $1(\mathrm{E} / 2,0,-\mathrm{E} / 2)$.

Table 1. Obtaining of three-level inverters

\begin{tabular}{|c|c|c|c|c|c|}
\hline $\boldsymbol{K i}$ & $\boldsymbol{T}_{\boldsymbol{i} \boldsymbol{1}}$ & $\boldsymbol{T}_{\boldsymbol{i} 2}$ & $\boldsymbol{T}_{\boldsymbol{i} 3}$ & $\boldsymbol{T}_{\boldsymbol{i} 4}$ & $\boldsymbol{V i \boldsymbol { o }}$ \\
\hline 1 & 1 & 1 & 0 & 0 & $\mathrm{E} / 2$ \\
\hline 0 & 0 & 1 & 1 & 0 & 0 \\
\hline-1 & 0 & 0 & 1 & 1 & $-\mathrm{E} / 2$ \\
\hline
\end{tabular}

The phase-to-neutral point voltage Vin is linked to Vio via:

$v_{i n}=v_{i o}+v_{n o}$

Assuming that the system is balanced, then:

$v_{a n}+v_{b n}+v_{c n}=0$ 
By substituting (3) in (2), the equation presented below is obtained:

$v_{n o}=1 / 3\left(v_{a o}+v_{b o}+v_{c o}\right)$

The expressions of instantaneous inverter phase output voltages are obtained by replacing (4) in (2):

$\left[\begin{array}{l}v_{a n} \\ v_{b n} \\ v_{c n}\end{array}\right]=\left[\begin{array}{c}2 / 3-1 / 3-1 / 3 \\ -1 / 32 / 3-1 / 3 \\ -1 / 3-1 / 32 / 3\end{array}\right] \cdot\left[\begin{array}{c}v_{a o} \\ v_{b o} \\ v_{c o}\end{array}\right]$

The line to line voltages are determined by the following equation:

$\left[\begin{array}{l}v_{a b} \\ v_{b c} \\ v_{c a}\end{array}\right]=\left[\begin{array}{ccc}1 & -1 & 1 \\ 0 & 1 & -1 \\ -1 & 0 & 0\end{array}\right] \cdot\left[\begin{array}{l}v_{a o} \\ v_{b o} \\ v_{c o}\end{array}\right]$

\subsection{Reference current calculation}

Several methods were proposed for the identification of the harmonic current references. Mainly, the methods based on the FFT (Fast Fourier Transformation) in the frequency domain and the methods based on instantaneous power calculation in the time domain. In this study, the $p q$ theory method is used allowing the compensation of harmonic currents, reactive power and unbalanced currents. The reference currents (harmonic currents) identification is based on $\alpha-\beta$ transformation to obtain real and imaginary powers. The voltages (VS1, VS2, VS3) and currents (IS1, IS2, IS3) are transformed to bi-phase system according to the following equation [7-9]:

$\left[\begin{array}{l}X_{s \alpha} \\ X_{s \beta}\end{array}\right]=\sqrt{\frac{2}{3}}\left[\begin{array}{ccc}1 & -\frac{1}{2} & -\frac{1}{2} \\ 0 & \frac{\sqrt{3}}{2} & -\frac{\sqrt{3}}{2}\end{array}\right] \cdot\left[\begin{array}{l}X_{1} \\ X_{2} \\ X_{3}\end{array}\right]$

The instantaneous active and reactive powers of the system are calculated as follows:

$\left[\begin{array}{c}p \\ q\end{array}\right]=\left[\begin{array}{cc}v_{s \alpha} & v_{s \beta} \\ -v_{s \beta} & v_{s \alpha}\end{array}\right] \cdot\left[\begin{array}{l}i_{c \alpha} \\ i_{c \beta}\end{array}\right]$

Instantaneous powers are composed from a constant part and a variable part corresponding to fundamental and harmonic currents respectively.

$\left[\begin{array}{l}i_{c \alpha} \\ i_{c \beta}\end{array}\right]=\frac{1}{v_{s \alpha}^{2}+v_{s \beta}^{2}}\left[\begin{array}{cc}v_{s \alpha} & -v_{s \beta} \\ v_{s \beta} & v_{s \alpha}\end{array}\right] \cdot\left[\begin{array}{l}\tilde{p} \\ \tilde{q}\end{array}\right]$

\section{CURRENT CONTROL BY HYSTERESIS}

The method is based on the comparison of the difference $\varepsilon$ between the current reference and the measured currents with a fixed band. Each violation of this band gives a switching command switches to Fig 3.

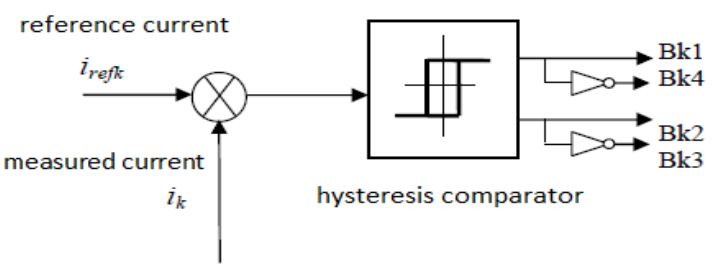

Figure 3. Principle of current control by hysteresis

\subsection{Hysteresis control algorithm for the three-level inverter}

The Bks control commands of the switches of the arm $\mathrm{k}$ are given by the following algorithm:

$$
\left\{\begin{array}{l}
S i\left|\left(\varepsilon_{k} \geq h\right) \&\left(\varepsilon_{k \leq 2 h}\right)\right| o u \mid\left(\varepsilon_{k} \leq-h\right) \&\left(\varepsilon_{k \geq-2 h)}\right) \Rightarrow B_{k 1}=0 \& B_{k 2}=1 \\
\operatorname{Si}\left(\varepsilon_{k<2} h\right) \Rightarrow B_{k 1}=0 \& B_{k 2}=0 \\
S i\left(\varepsilon_{k}>2 h\right) \Rightarrow B_{k 1}=1 \& B_{k 2}=1
\end{array}\right.
$$

\section{FUZZY LOGIC CURRENT CONTROLLER}

The main component of an active filter is the current controller. Generally the classical hysteresis controller is used to generate pulses to the PWM inverter; it is very stable and generates a minimum noise. Recently, fuzzy logic controllers (FLCs) have been interest a good alternative in more application. The advantage of fuzzy systems are that they do not need an accurate mathematical model, they can work with imprecise inputs, can handle non-linearity, and they are more robust than conventional nonlinear controllers.
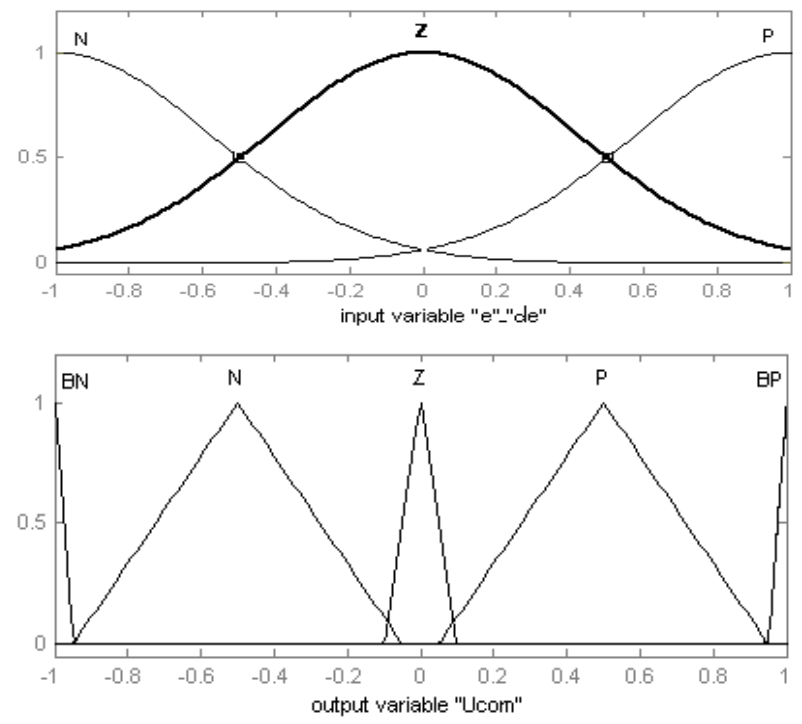

Figure 4. Membership function for the inputs and output variables

Fuzzy logic control is the evaluation of a set of simple linguistic rules to determine the control action. To develop the rules of the fuzzy logic, we need good understand of the process to be controlled, but it does not require a complicated mathematical model. The desired switching signals for the filter inverter circuit are determined according to the error in the filter current. In this case, the fuzzy logic current controller 
has two inputs, named error $e$ and change of error $d e$ and one output named $s$. Here the error $e$ and change of error $d e$ are the input variable for the system. To convert it into linguistic variable, we use three fuzzy sets:

$\mathrm{N}$ (Negative), ZE (Zero) and P (Positive). Figure 4 shows the membership functions used in fuzzification.

The fuzzy controller for every phase is characterized for the following:

- Three fuzzy sets for each input,

- Five fuzzy sets for each output,

- Triangular and trapezoidal membership functions,

- Implication using the "min" operator,

- Mamdani fuzzy inference mechanism based on fuzzy implication.

- Defuzzification using the "centroid" method

The linguistic rules for the fuzzy current controller are as follows:

1. If error is Negative and error rate is Negative Then output is Big Negative,
2. If error is Zero and error rate is Negative Then output is Positive,

3. If error is Positive and error rate is Negative Then output is Big Positive,

4. If error is Negative and error rate is Negative Then output in Big Negative,

5. If error is Zero and error rate is Zero Then output is Zero, 6. If error is Positive and error rate is Zero Then output is Big Positive,

7. If error is Negative and error rate is Positive Big Then output is Big Negative,

8. If error is Zero and error rate is Positive Then output is Negative,

9. If error is Positive and error rate is Positive Then output is Big Positive.

The generation process of switching signals is given by Figure 5.

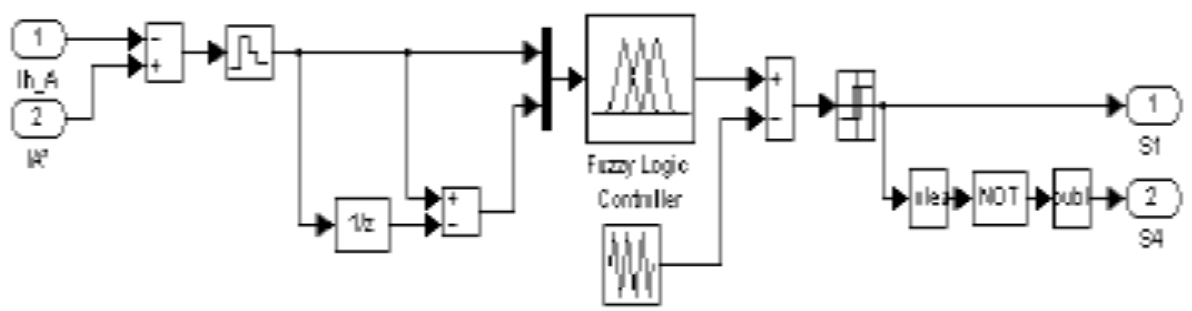

Figure 5. Generation process of switching signals

\section{DC CAPACITOR VOLTAGE CONTROL}

The capacitors $(C 1$ and $C 2)$ average voltage $(V d c 1, V d c 2)$ has to be maintained at a fixed value. The main cause of its variation is the active filter switching losses and output filter. To ensure inverter permanent and continuous voltage supply, a controlled scheme is adopted as illustrated in Figure 6.

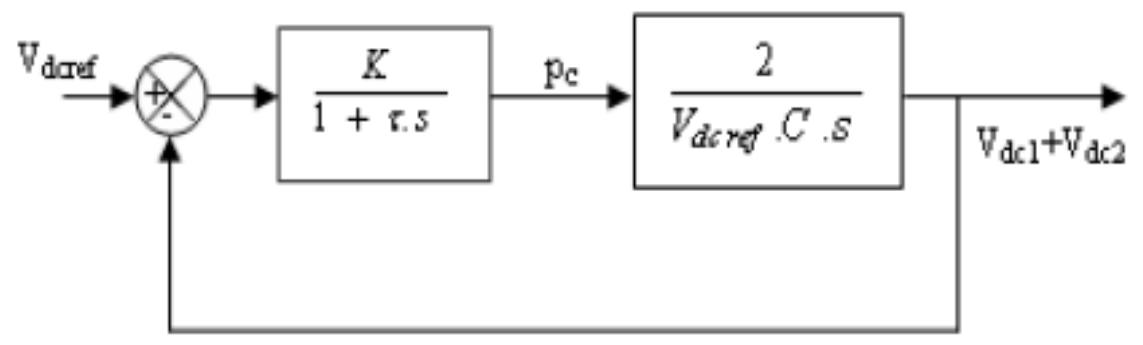

Figure 6. Dc voltage control block

\section{RESULTS OF THE SIMULATION}

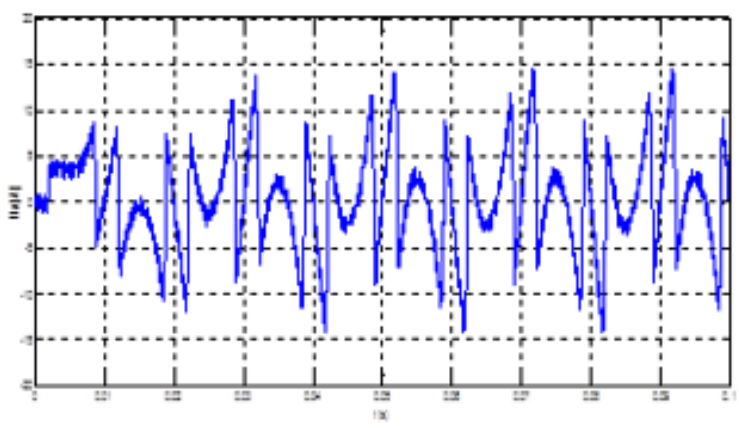

6.1 Simulations results using conventional hysteresis controller a band $\delta h=0.1 \mathrm{~A}$ :

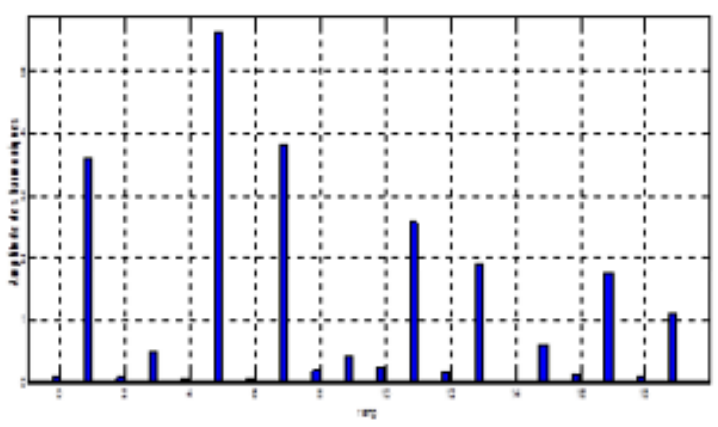



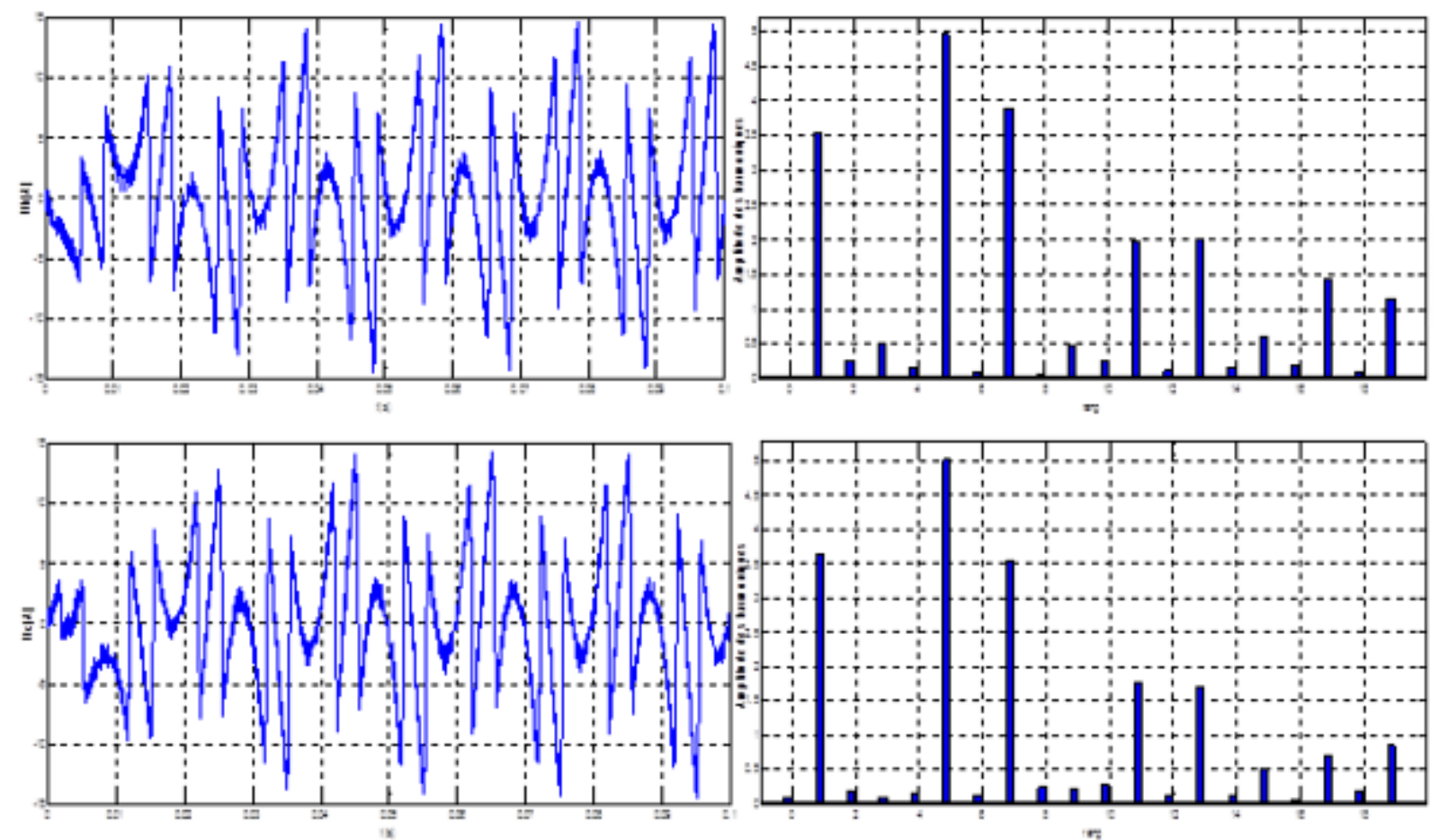

Figure 7. Currents injected by the inverter and their frequency spectra for the hysteresis control $(\Delta \mathrm{h}=0.1 \mathrm{~A})$
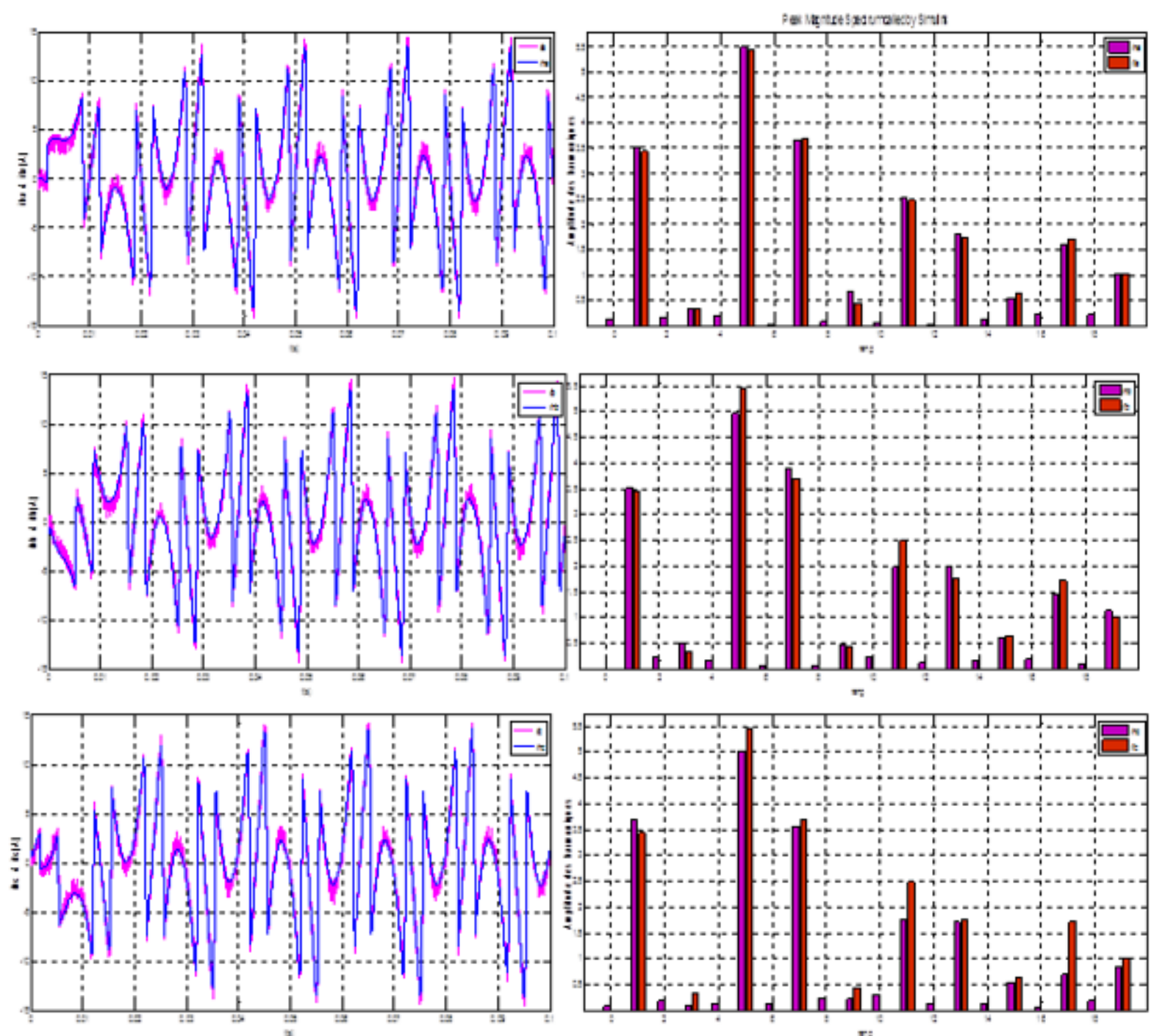

Figure 8. Reference currents, injected and their frequency spectra for the hysteresis control $(\Delta \mathrm{h}=0.1 \mathrm{~A})$ 

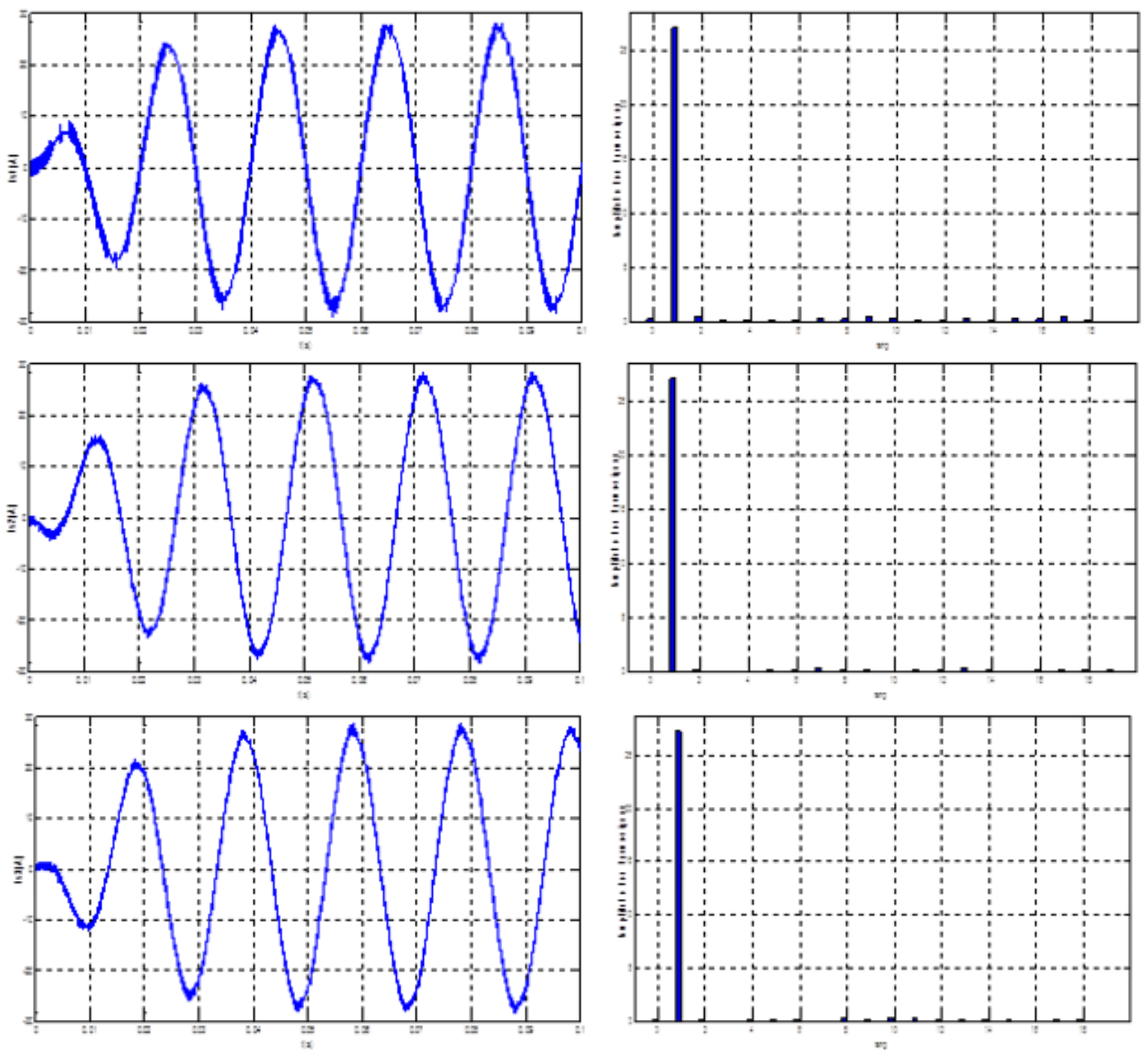

Figure 9. Source currents after filtering and their frequency spectra for the hysteresis control $(\Delta h=0.1 \mathrm{~A})$ 6.2 Simulations results using fuzzy controller
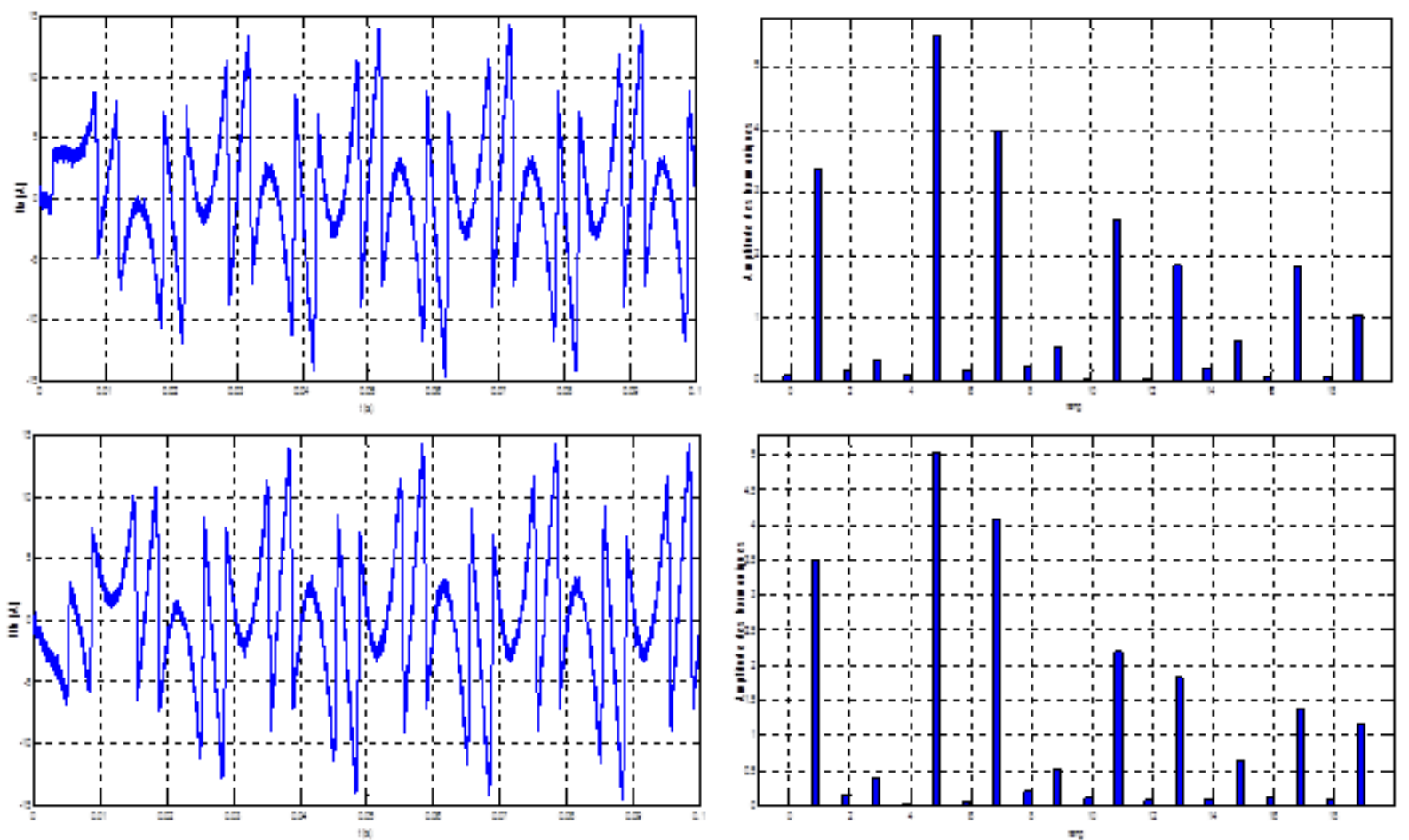

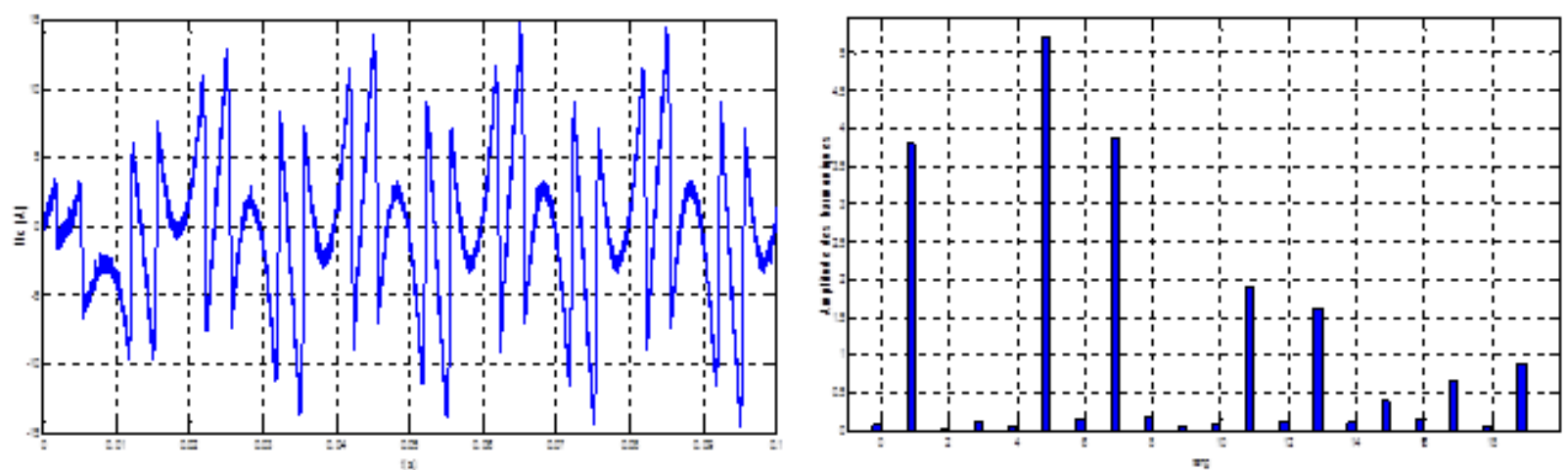

Figure 10. Currents injected by the inverter and their frequency spectra using Fuzzy Logic controller
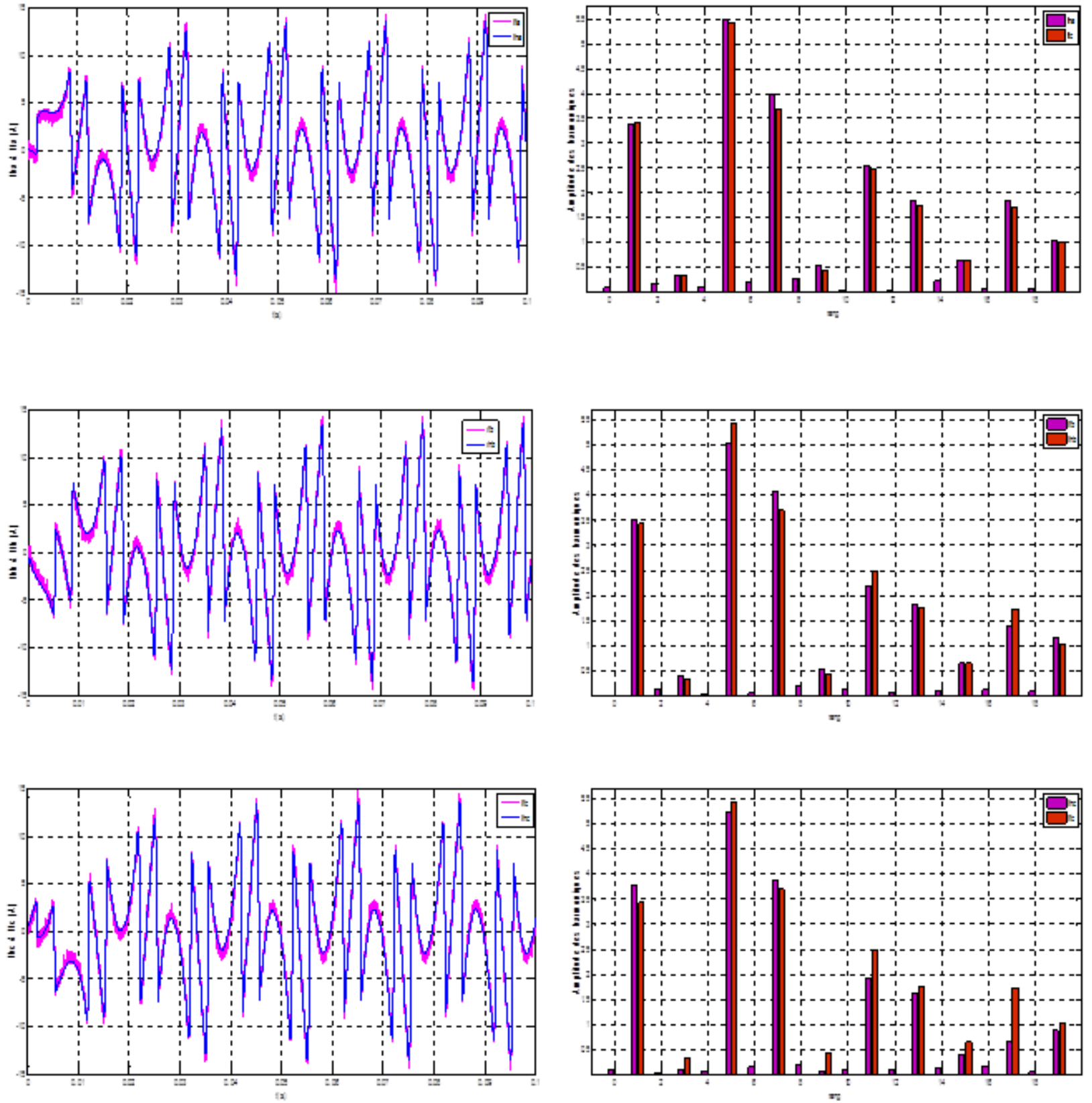

Figure 11. Reference currents, injected and their frequency spectra using Fuzzy Logic controller 

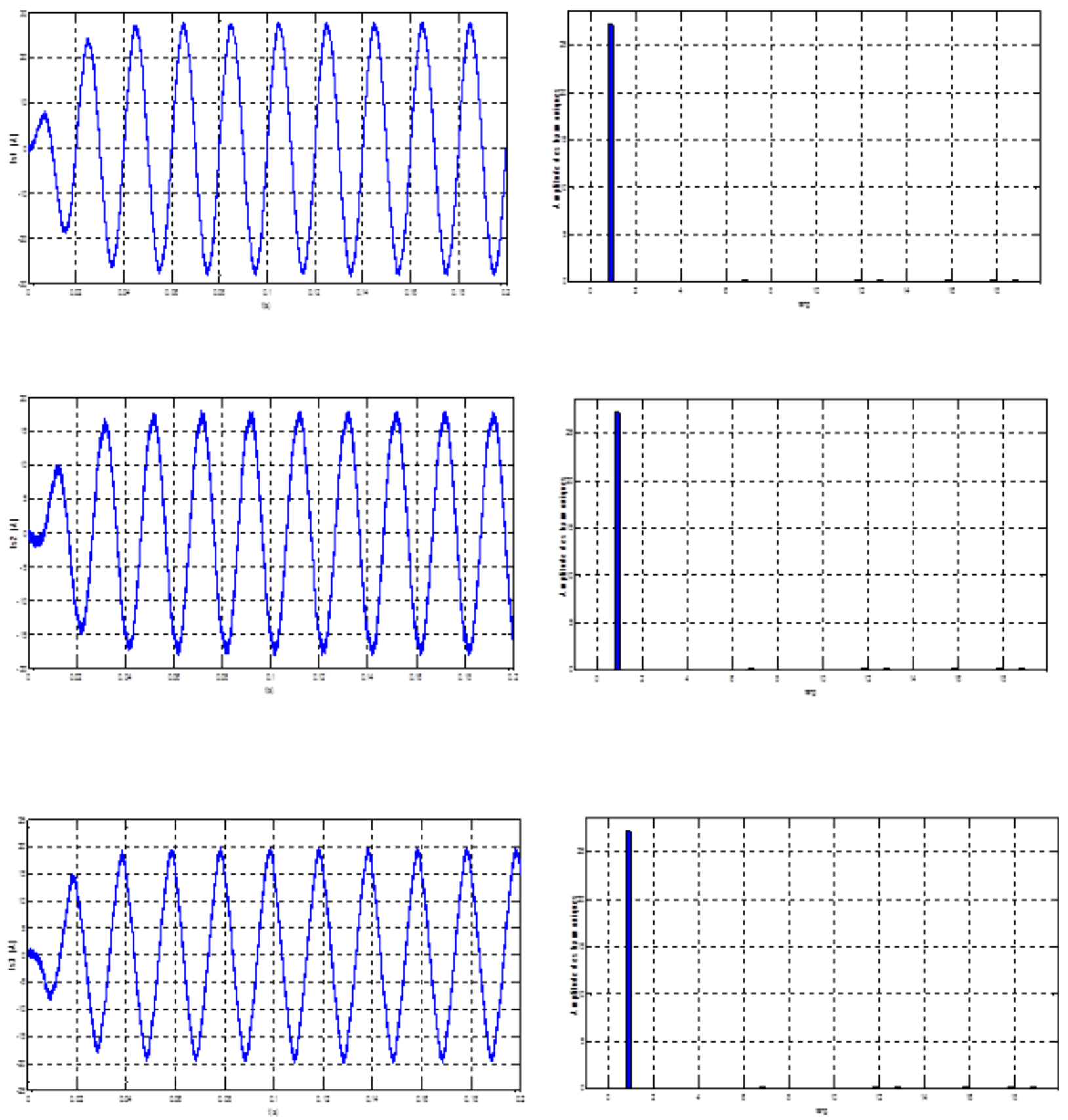

Figure 12. Source currents after filtering and their frequency spectra using Fuzzy Logic controller

\section{RESULTS AND DISCUSSIONS}

We can see from the simulation curves (figure 9) and (Figure 12) that the current in the network becomes almost sinusoidal as soon as the shunt active power is integrated. This is verified for both commands (hysteresis and fuzzy logic controller). Reference currents are well identified by the instantaneous powers method which ensures an excellent simulation. This also allows to inject harmonic currents to the network equal to those generated by the load and of opposite phases. The flow source side then becomes sinusoidal.

Figure 9 shows the simulated waveforms of the source current and harmonic spectrum source current after compensation using Hysteresis controller.

The reduction of the hysteresis band leads to an improvement of the quality of the current THD $=2.45 \%$ for $\Delta \mathrm{h}=0.1$.
The source current and injected current after APF application using fuzzy controller are respectively shown in Figure 11. The waveforms of source current after compensation are simultaneously and harmonic spectrum of the source current after compensation is shown in Figure 12.

The reduction of the fuzzy controller leads to an improvement of the quality of the current THD $=2.12 \%$.

\section{CONCLUSION}

In the present paper, three -level (NPC) shunt active filter with neutral-point diode clamped inverter based on fuzzy logic current controller is presented. Use of the filter is aimed at achieving the elimination of harmonics introduced by nonlinear loads. Several simulations under different conditions are performed using hysteresis and fuzzy current 
controllers. The results show the superiority and effectiveness of the proposed fuzzy controller in terms of eliminating harmonics, response time, and magnitude of source current during transient period. The THDi is significantly reduced of $2.12 \%$ for fuzzy controller (with shunt APF) in conformity with the IEEE standard norms (THD $<5 \%$ ). The current source after compensation is sinusoidal and in phase with the line voltage source; the power factor is nearly equal to unity. Hence, the proposed fuzzy logic current controller is an excellent candidate to control shunt active filters based on multilevel inverter topology toward eliminating the harmonic currents and improving the power factor.

\section{REFERENCES}

[1] Aredes M, Hafner J, Heumann. (1997).Three-phase fourwire shunt active filter control strategies. IEEE Transactions on Power Electronics 12(2): 311-318. https://doi.org/10.1109/63.558748

[2] Khruathep U, Premrudeepreechacharn S, Kumsuwan Y. (2008). Implementation of shunt active power filter using source voltage and source current detection. 3rd IEEE Conference on Industrial Electronics and Applications, Industrial Electronics and Applications, pp. 2346-2351. https://doi.org/10.1109/ICIEA.2008.4582937

[3] Benyettou L, Benslimane T. (2017). Analysis of Transistor open fault diagnosis for shunt active power filters. Indonesian Journal of Electrical Engineering and Computer Science 5(3): 521-529. http://doi.org/10.11591/ijeecs.v5.i3.pp521-529

[4] Vodyakho O, Hackstein D, Steimel A, Kim T. (2008). Novel direct current-space vector control for shunt active power filters based on three-level inverters. TwentyThird Annual IEEE Applied Power Electronics Conference and Exposition, pp. 1868-1873. https://doi.org/10.1109/APEC.2008.4522981
[5] Bo RL, Chun HH, Yu TY, Chuan LY. (2003). Analysis and implementation of shunt active power filter with three-level PWM scheme. IEEE 2: 1580-1885. https://doi.org/10.1109/PEDS.2003.1283225

[6] Benyettou L, Benslimane T, Bentata K, Abdelkhalek O. (2015). Open transistor faults characterization novel method for cascaded h-bridge five-level three-phase shunt active power filter. AMSE Journals, Modelling A 88(1): 53-70.

[7] Benyettou L, Benslimane T, Abdelkhalek O. (2017). Comparative study of different methods of active power compensation. AMSE Journals, Modelling A 90(4): 310327.

[8] José Luis Monroy-Morales. (2017). An active power filter based on a three-level inverter and 3D-SVPWM for selective harmonic and reactive compensation. Energies, 10(3): 1-23

[9] Benyettou L, Benslimane T, Bentata K. (2014). Faults diagnosis in cascaded h-bridge seven-level shunt active power filter. The Mediterranean Journal of Measurement and Control 10(4): 300-310.

\section{APPENDIX}

Abbreviations and symbols are listed below:

(1) NPC. Neutral Point Clamped

(2) DC. Direct current

(3) PWM. Pulse Width Modulation

(4) FLCs. Fuzzy logic controllers

(5) THD. Total Harmonic Distortion

(6) $\mathrm{APF}$. Shunt active power 